Published in final edited form as:

J Am Chem Soc. 2019 May 01; 141(17): 6864-6868. doi:10.1021/jacs.9b03113.

\title{
Conversion of Aldehydes to Branched or Linear Ketones via Regiodivergent Rhodium-Catalyzed Vinyl Bromide Reductive Coupling-Redox Isomerization Mediated by Formate
}

\author{
Robert A. Swyka\#, William G. Shuler", Brian J. Spinello, Wandi Zhang, Chunling Lan, and \\ Michael J. Krische \\ University of Texas at Austin, Department of Chemistry, Austin, TX 78712, USA \\ \# These authors contributed equally to this work.
}

\begin{abstract}
A regiodivergent catalytic method for direct conversion of aldehydes to branched or linear alkyl ketones is described. Rhodium complexes modified by $\mathrm{P}^{t} \mathrm{Bu}_{2} \mathrm{Me}$, catalyze formate-mediated aldehyde-vinyl bromide reductive coupling-redox isomerization to form branched ketones. Use of the less strongly coordinating ligand, $\mathrm{PPh}_{3}$, promotes vinyl- to allylrhodium isomerization en route to linear ketones. This method bypasses the 3 -step sequence often used to convert aldehydes to ketones involving the addition of premetalated reagents to Weinreb or morpholine amides.
\end{abstract}

\section{Graphical Abstract}

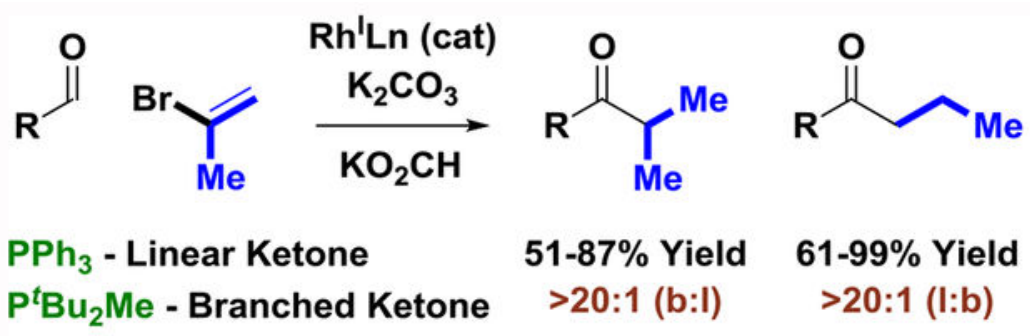

$\Rightarrow$ No Stoichiometric Metals, Non-Cryogenic, Redox-Neutral

Ketones are of commercial significance across the pharmaceutical, agrochemical and flavorfragrance industries. Convergent manufacturing routes to ketones from aldehydes often rely on 3-step sequences involving the addition of stoichiometric organometallic reagents to

\footnotetext{
Corresponding Author. mkrische@mail.utexas.edu.

Supporting Information Available: Experimental procedures and spectral data. This material is available free of charge via the internet at http://pubs.acs.org.

The authors declare no competing financial interest.

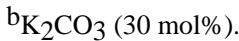

$\mathrm{c}^{\mathrm{C}} \mathrm{K}_{2} \mathrm{CO}_{3}$ omitted.

${ }^{\mathrm{d}} \mathrm{DME}(0.2 \mathrm{M}), 130^{\circ} \mathrm{C}$.

$\mathrm{e} 120^{\circ} \mathrm{C}$. Yields are of chromatographically isolated material. As the isomeric ketone products are inseparable via conventional flash chromatography, isomeric ratios were determined from ${ }^{1} \mathrm{H}$ NMR analysis of isolated products.
} 
alkoxy-amides, ${ }^{1}$ such as the Weinreb amide ${ }^{2,3}$ or morpholine amides (Figure 1). ${ }^{4}$ Alternatively, 2-step ketone syntheses can be achieved through the addition of vinylmetal reagents to aldehydes followed by internal redox-isomerization of the resulting allylic alcohols. ${ }^{5,6}$ In connection with longstanding efforts to develop reductive C-C couplings via transfer hydrogenation, ${ }^{7,8}$ we envisioned a direct protocol for the conversion of aldehydes to ketones wherein vinyl halide-carbonyl reductive coupling is followed by internal redoxisomerization. This transformation finds precedent in our recently reported rhodiumcatalyzed aryl halide-aldehyde reductive coupling mediated by sodium formate, ${ }^{9,10}$ as well as related redox-neutral aryl halide-aldehyde C-C couplings to form aryl ketones. ${ }^{11}$ As described herein, our pursuit of this goal has resulted in the development of a direct, regiodivergent ${ }^{12}$ vinyl bromide-aldehyde reductive coupling to form either linear or branched ketone products. ${ }^{13-16}$

In an initial experiment, piperonal 1a (100 mol\%) and 2-bromopropene 2a (200 mol\%) were exposed to $\mathrm{NaO}_{2} \mathrm{CH}(300 \mathrm{~mol} \%)$ and $\mathrm{Cs}_{2} \mathrm{CO}_{3}(100 \mathrm{~mol} \%)$ in the presence of the catalyst assembled from $\mathrm{Rh}(\mathrm{acac})(\mathrm{CO})_{2}(5 \mathrm{~mol} \%)$ and $\mathrm{P}^{\mathrm{t}} \mathrm{Bu}_{2} \mathrm{Me}(11 \mathrm{~mol} \%)$ in DME $(0.2 \mathrm{M})$ at $130{ }^{\circ} \mathrm{C} .{ }^{9}$ The anticipated branched ketone product $3 \mathrm{a}$ was formed in $45 \%$ yield after isolation by flash column chromatography (Table 1, entry 1 ). A survey of phosphine ligands was undertaken (Table 1, entries 1-10). Remarkably, use of $\mathrm{PPh}_{3}$ under otherwise identical conditions led to a $48 \%$ yield of the linear ketone product $4 \mathbf{a} .{ }^{13}$ The isolated yield of linear ketone $4 \mathbf{a}$ was elevated to $77 \%$ yield upon use of $\mathrm{KO}_{2} \mathrm{CH}(300 \mathrm{~mol} \%)$ and $\mathrm{K}_{2} \mathrm{CO}_{3}(100 \mathrm{~mol}$ $\%)$ (Table 1, entry 12). Finally, by lowering the loading of $\mathrm{K}_{2} \mathrm{CO}_{3}(70 \mathrm{~mol} \%)$, the formation of a competing elimination side-product, 5-(1-butenyl)-1,3-benzodioxole, could be attenuated, enabling formation of linear ketone 4a in $92 \%$ yield (Table 1, entry 13). Dry $\mathrm{KO}_{2} \mathrm{CH}$ (vide infra) and dry DME were required for optimal isolated yields. Using $\mathrm{P}^{t} \mathrm{Bu}_{2} \mathrm{Me}$ as ligand under these conditions delivered the branched ketone 3a in 54\% yield (Table 1, entry 14$)$, and at higher concentration $(0.4 \mathrm{M})$ the isolated yield of $\mathbf{3 a}$ was increased to $80 \%$ (Table 1, entry 15). Notably, while optimal conditions for formation of the linear and branched ketones 3a and $4 \mathbf{a}$ differ primarily on the basis of ligand (Table 1, entries 13 vs $15)$, virtually complete partitioning of these constitutionally isomeric products was observed (>40:1 isomeric ratios were observed by ${ }^{1} \mathrm{H}$ NMR analysis of crude reaction mixtures).

To evaluate reaction scope, optimal conditions identified for the conversion of piperonal 1a to the constitutionally isomeric branched and linear ketone products $\mathbf{3 a}$ and $\mathbf{4 a}$ were applied to diverse aldehydes 1a-1r (Table 2). Aromatic aldehydes 1a-1k, heteroaromatic aldehydes 1l-1m, and aliphatic aldehydes $1 \mathbf{n}-\mathbf{1 r}$ were converted to the respective branched ketones $\mathbf{3 a - 3 r}$ or linear ketones $\mathbf{4 a - 4 r}$ in generally good yields. With the exception of branched ketone $\mathbf{3 m}$, the chromatographically isolated products appeared to be isomerically pure by ${ }^{1} \mathrm{H}$ NMR analysis. For $\mathbf{3 m}$, delocalization of the pyrazole nitrogen might deactivate the aldehyde toward insertion, providing a kinetic window for competing branched-to-linear isomerization. For optimal results, it was necessary to use freshly distilled DME and $\mathrm{KO}_{2} \mathrm{CH}$ recrystallized from ethanol. The recrystallized $\mathrm{KO}_{2} \mathrm{CH}$ was collected by filtration and washed with diethyl ether under an inert atmosphere. If wet $\mathrm{KO}_{2} \mathrm{CH}$ is used, significant quantities of aldehyde reduction and oxidative esterification is observed. For reactions run 
on a $1 \mathrm{mmol}$ scale, it was important to utilize a narrow reaction vessel at low volume (10$20 \%$ ).

The feasibility of utilizing alternate vinyl bromides $\mathbf{2 b}$ and $\mathbf{2 c}$ in regiodivergent reductive coupling-internal redoxisomerization was briefly investigated in reactions of piperonal $\mathbf{1 a}$. Under optimal conditions using $\mathrm{P}^{t} \mathrm{Bu}_{2} \mathrm{Me}$ as ligand, the anticipated branched ketones $3 \mathbf{s}$ and 3t were formed in good yields (eq. 1). However, when optimal conditions for formation of the linear products using $\mathrm{PPh}_{3}$ as ligand were applied, the linear ketones were not obtained in isomerically pure form. This limitation was easily overcome through use of the isomeric terminal vinyl bromides iso-2b and iso-2c, which deliver the constitutionally isomeric linear ketones $\mathbf{4 s}$ and $\mathbf{4 t}$, albeit in modest yield (eq. 2).
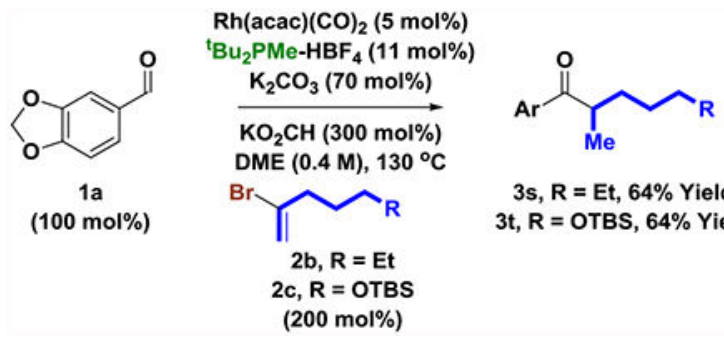

(100 $\mathrm{mol} \%)$

3s, R = Et, $64 \%$ Yield

$3 t, R=$ OTBS, $64 \%$ Yield

2c, $R=$ OTBS

(eq. 1)
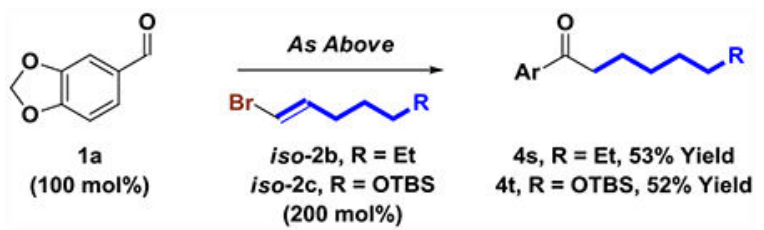

(eq. 2)

To gain insight into the catalytic cycle, a series of deuterium labelling experiments were performed (eq. 3-6). Exposure of aldehyde deuterio-1a to 2-bromopropene 2a to standard conditions favoring formation of the branched regioisomer delivers deuterio-3a, which incorporates a single deuterium atom $\left(>95 \%{ }^{2} \mathrm{H}\right)$ at the methyl group of the isopropyl ketone (eq. 3). As deuterio-3a is postulated to arise via isomerization of the corresponding allylic alcohol deuterio-iso-3a, the latter compound was subjected to standard conditions favoring formation of the branched regioisomer (eq. 4). In this case, deuterium was incorporated at both the methyl group $\left(92 \%{ }^{2} \mathrm{H}\right)$ and the methine moieties $\left(8 \%{ }^{2} \mathrm{H}\right)$ of the isopropyl ketone. Similarly, deuterio-1a and the homoallylic alcohol deuterio-iso-4a were exposed to standard conditions favoring formation of the linear regioisomer (eq. 5 and 6). The resulting $n$-propyl ketones deuterio-4a and deuterio-4a' display similar but non-identical patterns of deuterium incorporation. These data corroborate allylic and homoallylic alcohols as reactive intermediates en route to the branched and linear ketone products, respectively. The nonidentical patterns of deuterium incorporation between deuterio-3a vs deuterio-3a' and 
deuterio-4a vs deuterio-4a' suggests redox isomerization may occur in part from the kinetic rhodium alkoxide.

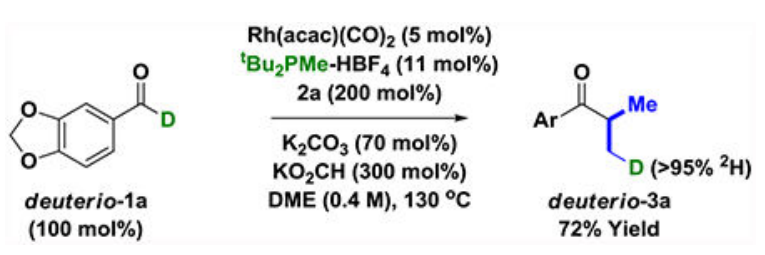

(eq. 3)

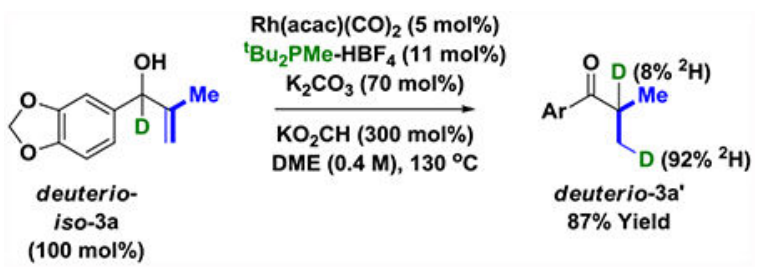

(eq. 4)

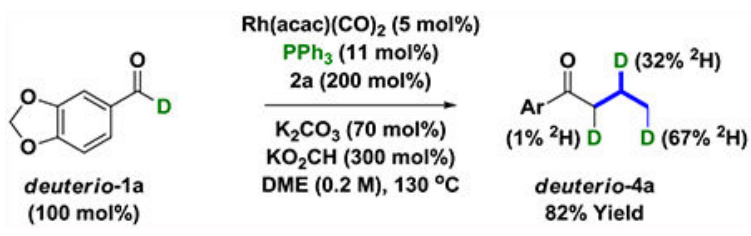

(eq. 5)

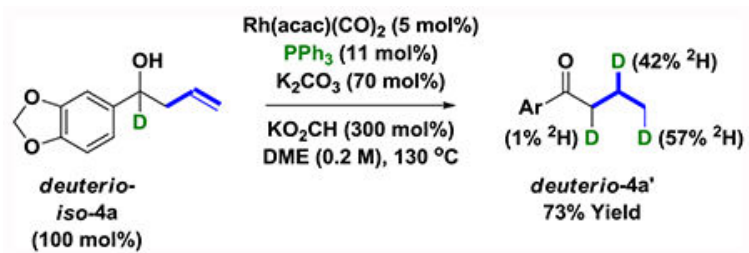

(eq. 6)

Based on the collective data the following catalytic cycle is proposed (Scheme 1). Vinyl bromide oxidative addition forms the indicated vinylrhodium(III) species. ${ }^{17}$ For the strong $\sigma$-donor ligand $\mathrm{P}^{t} \mathrm{Bu}_{2} \mathrm{Me}$, aldehyde insertion occurs to form a rhodium alkoxide. ${ }^{18}$ The bromide moiety of the kinetic rhodium alkoxide can react with $\mathrm{KO}_{2} \mathrm{CH}$ to form a hydride, which upon $\mathrm{O}-\mathrm{H}$ reductive elimination ${ }^{19}$ delivers the allylic alcohol and, therefrom, the branched ketone. Alternatively, the kinetic rhodium alkoxide can undergo $\beta$-hydride elimination to form an enone, which undergoes conjugate reduction to form the the branched 
ketone (not shown). For the weak $\sigma$-donor ligand $\mathrm{PPh}_{3}$, phosphine dissociation at the stage of the vinylrhodium(III) intermediate triggers $\beta$-hydride elimination to form a transient allene, which upon hydrometalation delivers an allylrhodium(III) species.13 Aldehyde insertion delivers a homoallylic rhodium alkoxide, ${ }^{18}$ which is ultimately converted to the linear ketone. Coupling products were not formed in reactions using other weakly coordinating monodentate ligands, for example, $\mathrm{P}(\mathrm{OPh})_{3}, \mathrm{P}\left(\mathrm{C}_{6} \mathrm{~F}_{5}\right)_{3}$ or $\mathrm{P}(2-\mathrm{Fur})_{3}$.

In summary, we report a catalytic method enabling direct conversion of aldehydes to alkyl ketones $^{20,21}$ and establish conditions for regiodivergent access to either the branched or linear ketone isomers. Specifically, using the rhodium catalyst modified by $\mathrm{P}^{t} \mathrm{Bu}_{2} \mathrm{Me}$, vinyl halide-aldehyde reductive coupling mediated by formate is followed by redox isomerization of the resulting allylic alcohol to form branched ketone products. In contrast, use of a less strongly coordinating ligand, $\mathrm{Ph}_{3} \mathrm{P}$, promotes vinyl- to allylrhodium isomerization en route to linear ketones. This method bypasses the 3-step sequence often used to convert aldehydes to ketones involving the addition of stoichiometric organometallic reagents to Weinreb or morpholine amides.

\section{Supplementary Material}

Refer to Web version on PubMed Central for supplementary material.

\section{Acknowledgments.}

The Robert A. Welch Foundation (F-0038), the NIH-NIGMS (RO1-GM069445). Eli Lilly and Company is acknowledged for LIFA postdoctoral fellowship funding (R.A.S.).

\section{REFERENCES}

1. O’Neill BT In Comprehensive Organic Synthesis Vol. 1; p 397 Trost BM, Fleming I Eds.; Pergamon: Oxford, 1991.

2. Nahm S; Weinreb SM $N$-Methoxy- $N$-Methylamides as Effective Acylating Agents. Tetrahedron Lett 1981, 22, 3815-3818.

3. For selected reviews on the synthesis of ketones from Weinreb amides, see:(a)Balasubramaniam S; Aidhen IS The growing synthetic utility of the Weinreb amide. Synthesis 2008, 3707-3738.

(b)Davies SG; Fletcher AM; Thomson JE Direct asymmetric syntheses of chiral aldehydes and ketones via $\mathrm{N}$-acyl chiral auxiliary derivatives including chiral Weinreb amide equivalents. Chem. Comm 2013, 49, 8586-8598. [PubMed: 23959006] (c)Nowak M Weinreb Amides. Synlett 2015, 26, 561-562.

4. Martín R Romea P Tey C; Urpí F; Vilarrasa J Simple and efficient preparation of ketones from morpholine amides. Synlett 1997, 1414-1416.

5. For selected reviews on metal-catalyzed internal redox isomerization of olefinic alcohols to form ketones, see:(a)Uma R; Crevisy C; Gree R Transposition of Allylic Alcohols into Carbonyl Compounds Mediated by Transition Metal Complexes. Chem. Rev 2003, 103, 27-51. [PubMed: 12517180] (b)Mantilli L; Mazet C Platinum Metals in the Catalytic Asymmetric Isomerization of Allylic Alcohols. Chem. Lett 2011, 40, 341-344.(c)Cahard D; Gaillard S; Renaud J-L Asymmetric isomerization of allylic alcohols. Tetrahedron Lett 2015, 56, 6159-6169.

6 . For a recent example of enantioselective rhodium-catalyzed internal redox isomerization of homoallylic and bishomoallylic secondary alcohols, see:Huang R-Z; Lau KK; Li Z; Liu T-L; Zhao YRhodium-Catalyzed Enantioconvergent Isomerization of Homoallylic and Bishomoallylic Secondary Alcohols J. Am. Chem. Soc 2018, 140, 14647-14654. [PubMed: 30354081] 
7. For selected reviews on transfer hydrogenative reductive coupling, see:(a)Iida H; Krische MJ Catalytic Reductive Coupling of Alkenes and Alkynes to Carbonyl Compounds and Imines Mediated by Hydrogen. Top. Curr. Chem 2007, 279, 77-104.(b)Hassan A; Krische MJ Unlocking Hydrogenation for $\mathrm{C}-\mathrm{C}$ Bond Formation: A Brief Overview of Enantioselective Methods. Org. Process Res. Devel 2011, 15, 1236-1242. [PubMed: 22125398] (c)Moran J; Krische MJ Formation of C-C Bonds via Ruthenium Catalyzed Transfer Hydrogenation. Pure Appl. Chem 2012, 84, 1729-1739. [PubMed: 23430602] (d)Ketcham JM; Shin I; Montgomery TP; Krische MJ Catalytic Enantioselective C $-\mathrm{H}$ Functionalization of Alcohols by Redox-Triggered Carbonyl Addition: Borrowing Hydrogen, Returning Carbon. Angew. Chem. Int. Ed 2014, 53, 9142-9150.(e)Nguyen KD; Park BY; Luong T; Sato H; Garza VJ; Krische MJ Metal-catalyzed reductive coupling of olefin-derived nucleophiles: Reinventing carbonyl addition. Science 2016, 354, No. aah5133.(f)Kim SW; Zhang W; Krische MJ Catalytic Enantioselective Carbonyl Allylation and Propargylation via Alcohol-Mediated Hydrogen Transfer: Merging the Chemistry of Grignard and Sabatier Acc. Chem. Res 2017, 50, 2371-2380. [PubMed: 28792731]

8. For general reviews on carbonyl reductive coupling, see:(a)Moragas T; Correa A; Martin. R. MetalCatalyzed Reductive Coupling Reactions of Organic Halides with Carbonyl-Type Compounds. Chem. Eur. J 2014, 20, 8242-8258. [PubMed: 24905555] (b)Holmes M; Schwartz LA; Krische MJ Intermolecular Metal-Catalyzed Reductive Coupling of Dienes, Allenes, and Enynes with Carbonyl Compounds and Imines. Chem. Rev 2018, 118, 6026-6052. [PubMed: 29897740]

9. Swyka RA; Zhang W; Richardson J; Ruble JC; Krische MJ Rhodium-Catalyzed Aldehyde Arylation via Formate-Mediated Transfer Hydrogenation: Beyond Metallic Reductants in Grignard/NozakiHiyami-Kishi-Type Addition. J. Am. Chem. Soc 2019, 141, 1828-1832. [PubMed: 30693768]

10. For a related aryl halide-carbonyl reductive cyclization mediated by elemental hydrogen, see:Shin I; Ramgren SD; Krische MJ Reductive Cyclization of Halo-Ketones to form 3-hydroxy-2oxindoles via Palladium Catalyzed Hydrogenation: a Hydrogen-mediated Grignard Addition. Tetrahedron 2015, 71, 5776-5780. [PubMed: 26273111]

11. For redox-neutral catalytic aryl halide-aldehyde couplings to form ketone products, see: (a)Palladium: Satoh T; Itaya T; Miura M; Nomura M Palladium-Catalyzed Coupling Reaction of Salicylaldehydes with Aryl Iodides via Cleavage of the Aldehyde C-H Bond. Chem. Lett 1996, 25, 823-824.(b)Ko S; Kang B; Chang S Cooperative Catalysis by Ru and Pd for the Direct Coupling of a Chelating Aldehyde with Iodoarenes or Organostannanes. Angew. Chem. Int. Ed 2005, 44, 455-457.(c)Takemiya A; Hartwig JF Palladium-Catalyzed Synthesis of Aryl Ketones by Coupling of Aryl Bromides with an Acyl Anion Equivalent. J. Am. Chem. Soc 2006, 128, 1480014801. [PubMed: 17105278] (d)Ruan J; Saidi O; Iggo JA; Xiao J Direct Acylation of Aryl Bromides with Aldehydes by Palladium Catalysis. J. Am. Chem. Soc 2008, 130, 10510-10511. [PubMed: 18636731] (e)Zanardi A; Mata JA; Peris E Palladium Complexes with Triazolyldiylidene. Structural Features and Catalytic Applications. Organometallics 2009, 28, 1480-1483.(f)Adak L; Bhadra S; Ranu BC Palladium(0) Nanoparticle-catalyzed sp2 C-H Activation: A Convenient Route to alkyl-aryl Ketones by Direct Acylation of Aryl Bromides and Iodides with Aldehydes. Tet. Lett 2010, 51, 3811-3814.(g)Nowrouzi N; Motevalli S; Tarokh D Palladium-Catalyzed Direct C-H Arylation of 2-hydroxybenzaldehydes With Organic Halides in Neat Water. J. Mol. Cat. A: Chem 2015, 396, 224-230.(h)Nowrouzi N; Tarokh D PdCl 2 /DABCOCatalyzed Direct Arylation of 2-hydroxybenzaldehydes in $\mathrm{H}_{2}$ O. J. Iran Chem. Soc 2016, 13, 1493-1497.(i)Suchand B; Satyanarayana G Palladium-Catalyzed Environmentally Benign Acylation. J. Org. Chem 2016, 81, 6409-6423. [PubMed: 27377566] (j)Wakaki T; Togo T; Yoshidome D; Kuninobu Y; Kanai M Palladium-Catalyzed Synthesis of Diaryl Ketones from Aldehydes and (Hetero)Aryl Halides via C-H Bond Activation. ACS Catal 2018, 8, 3123-3128. (k)Rhodium: Ishiyama T; Hartwig JF A Heck-Type Reaction Involving Carbon-Heteroatom Double Bonds. Rhodium(I)-Catalyzed Coupling of Aryl Halides with N-Pyrazyl Aldimines. J. Am. Chem. Soc 2000, 122, 12043-12044.(1)Rao ML; Ramakrishna BS Rhodium-Catalyzed Directing-Group-Assisted Aldehydic C-H Arylations with Aryl Halides. Eur. J. Org. Chem 2017, 2017, 5080-5093.(m)Nickel: Huang Y-C; Majumdar KK; Cheng C-H Nickel-Catalyzed Coupling of Aryl Iodides with Aromatic Aldehydes: Chemoselective Synthesis of Ketones. J. Org. Chem 2002, 67, 1682-1684. [PubMed: 11871903] (n)Nowrouzi N; Zarei M; Roozbin F First Direct Access to 2-hydroxybenzophenones via Nickel-Catalyzed Cross-Coupling of 2Hydroxybenzaldehydes with Aryl Iodides. RSC Adv 2015, 5, 102448-102453.(o)Vandavasi JK; Hua X; Ben Hali ma H; Newman SG A Nickel-Catalyzed Carbonyl-Heck Reaction. Angew. 
Chem. Int. Ed 2017, 56, 15441-15445.(p)Photoredox: Zhang X; MacMillan DWC Direct Aldehyde C-H Arylation and Alkylation via the Combination of Nickel, Hydrogen Atom Transfer, and Photoredox Catalysis. J. Am. Chem. Soc 2017, 139, 11353-11356. [PubMed: 28780856] (q)Cobalt: Hu YL; Wu YP; Lu M Co (II)-C12 Alkyl Carbon Chain Multi-Functional Ionic Liquid Immobilized on Nano-SiO $2 \mathrm{Nano}_{-} \mathrm{SiO}_{2} @ \mathrm{CoCl}_{3}-\mathrm{C} 12 \mathrm{IL}$ as an Efficient Cooperative Catalyst for $\mathrm{C}-\mathrm{H}$ Activation by Direct Acylation of Aryl Halides with Aldehydes Appl. Organomet. Chem 2018, 32, e4096.

12. For an excellent review on regiodivergent catalysis to form constitutionally isomeric products, see:Funken N; Zhang Y-Q; Gansauer A Regiodivergent Catalysis: A Powerful Tool for Selective Catalysis. Chem. Eur. J 2017, 23, 19-32. [PubMed: 27813183]

13. Mechanistically related branched-to-linear isomerizations appear as undesired side-reactions in cross-couplings of secondary alkyl partners. For recent discussions, see:(a)Han C; Buchwald SL Negishi Coupling of Secondary Alkylzinc Halides with Aryl Bromides and Chlorides. J. Am. Chem. Soc 2009, 131, 7532-7533. [PubMed: 19441851] (b)Yang Y; Mustard TJL; Cheong P HaYeon; Buchwald, S. L. Palladium-Catalyzed Completely Linear-Selective Negishi Cross-Coupling of Allylzinc Halides with Aryl and Vinyl Electrophiles. Angew. Chem. Int. Ed 2013, 52, 14098 14102.(c)Zhang K-F; Christoffel F; Baudoin O Barbier-Negishi Coupling of Secondary Alkyl Bromides with Aryl and Alkenyl Triflates and Nonaflates Angew. Chem. Int. Ed 2018, 57, 19821986.(d)Cherney AH; Hedley SJ; Mennen SM; Tedrow JS Organometallics 2019, 38, 97-102.

14. Ligand-dependent partitioning of linear and branched C-C coupling products was observed in Suzuki-Miyaura couplings of 3,3-disubstituted and 3-monosubstituted allylboronates with (hetero)aryl halides:Yang Y; Buchwald SL Ligand-Controlled Palladium-Catalyzed Regiodivergent Suzuki-Miyaura Cross-Coupling of Allylboronates and Aryl Halides. J. Am. Chem. Soc 2013, 135, 10642-10645. [PubMed: 23837686]

15. For regiodivergent diene-carbonyl reductive couplings, see:Köpfer A; Sam B; Breit B; Krische MJ Regiodivergent Reductive Coupling of 2-Substituted Dienes to Formaldehyde Employing Ruthenium or Nickel Catalysts: Hydrohydroxymethylation via Transfer Hydrogenation. Chem. Sci 2013, 4, 1876-1880.

16. For regiodivergent styrene-carbonyl reductive couplings, see:Xiao H; Wang G Krische MJ Regioselective Hydrohydroxyalkylation of Styrene with Primary Alcohols or Aldehydes via Ruthenium Catalyzed C-C Bond Forming Transfer Hydrogenation. Angew. Chem. Int. Ed 2016, 55, 16119-16122.

17. For studies on the oxidative addition of aryl and vinyl halides to rhodium(I) complexes, see: (a)Monophosphine Complexes: Jiao Y; Brennessel WW; Jones WD Oxidative Addition of Chlorohydrocarbons to a Rhodium Tris(pyrazolyl)borate Complex. Organ-ometallics 2015, 34, 1552-1566.(b)Townsend NS; Chaplin AB; Abu Naser M; Thompson AL; Rees NH; Macgregor SA; Weller AS Reactivity of the Latent 12-Electron Fragment $\left[\mathrm{Rh}\left(\mathrm{PiBu}_{3}\right)_{2}\right]^{+}$with Aryl Bromides: Aryl-Br and Phosphine Ligand C-H Activation. Chem. Eur. J 2010, 16, 8376-8389. [PubMed: 20572181] (c)Chen S; Li Y; Zhao J; Li X Chelation-Assisted Carbon-Halogen Bond Activation by a Rhodium(I) Complex. Inorg. Chem 2009, 48, 1198-1206. [PubMed: 19105736] (d)Douglas TM; Chaplin AB; Weller AS Dihydrogen Loss from a 14-Electron Rhodium(III) Bis-Phosphine Dihydride To Give a Rhodium(I) Complex That Undergoes Oxidative Addition with Aryl Chlorides. Organometallics 2008, 27, 2918-2921.(e)Bisphosphine Complexes: Pike SD; Weller AS C-Cl Activation of the Weakly Coordinating Anion $\left[\mathrm{B}\left(3,5-\mathrm{Cl}_{2} \mathrm{C}_{6} \mathrm{H}_{3}\right)_{4}\right]-$ at a $\mathrm{Rh}(\mathrm{I})$ Centre in Solution and the Solid-State Dalton Trans 2013, 42, 12832-12835. [PubMed: 23884210] (f)Koenig A; Fischer C; Alberico E; Selle C; Drexler H-J; Baumann W; Heller D Oxidative Addition of Aryl Halides to Cationic Bis(phosphane)rhodium Complexes: Application in $\mathrm{C}-\mathrm{C}$ Bond Formation. Eur. J. Inorg. Chem 2017, 2040-2047.

18. For insertion of aldehyde $\mathrm{C}=\mathrm{O} \pi$-bonds into aryl-rhodium $\sigma$-bonds and related $\beta$-aryl eliminations, see:(a)Krug C; Hartwig JF Direct Observation of Aldehyde Insertion into Rhodium-Aryl and -Alkoxide Complexes. J. Am. Chem. Soc 2002, 124, 1674-1679. [PubMed: 11853443] (b)Zhao P; Incarvito CD; Hartwig JF Direct Observation of $\beta$-Aryl Eliminations from Rh(I) Alkoxides. J. Am. Chem. Soc 2006, 124, 3124-3125.

19. For O-H reductive elimination of metal alkoxides, see:(a)Rhodium: Milstein D Carbon-hydrogen vs. oxygen-hydrogen reductive elimination of methanol from a metal complex. Which is a more likely process? J. Am. Chem. Soc 1986, 108, 3525-3526.(b)Iridium: Glueck DS; Winslow LJN; 
Bergman RG Iridium Alkoxide and Amide Hydride Complexes. Synthesis, Reactivity, and the Mechanism of Oxygen-Hydrogen and Nitrogen-Hydrogen Reductive Elimination Organometallics 1991, 10, 1462-1479.(c)Blum O; Milstein D Direct Observation of O-H Reductive Elimination from Ir ${ }^{\mathrm{III}}$ Complexes Angew. Chem. Int Ed 1995, 34, 229-231.

20. Aldehydes can be directly converted to alkyl ketones under the conditions of rhodium-catalyzed alkene hydroacylation, however, intermolecular variants typically require use of aldehydes with $\beta$ chelating groups to suppress catalyst deactivation via aldehyde decarbonylation. For a review, see:Leung JC; Krische MJ Catalytic Intermolecular Hydroacylation of C-C $\pi$-Bonds in the Absence of Chelation Assistance. Chem. Sci 2012, 3, 2202-2209.

21. The direct conversion of aldehydes to alkyl ketones has been achieved via metal-catalyzed C-H activation-initiated carbonyl Heck reactions, however, such processes require directing groups and stoichiometric oxidants. For a review, see:Pan C; Jia X; Cheng J Transition-Metal-Catalyzed Synthesis of Aromatic Ketones via Direct C-H Bond Activation. Synthesis 2012, 677-685. 
Classical Ketone Synthesis via Addition of Organometallics to Amides

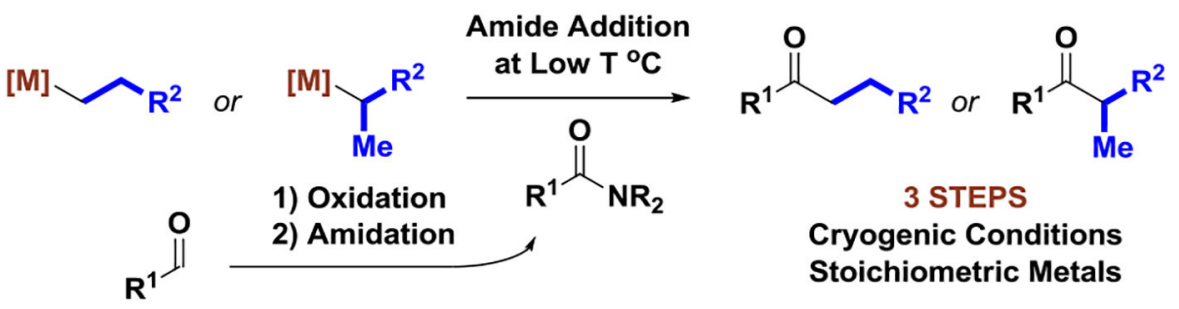

Metal-Catalyzed Internal Redox Isomerization of Allylic Alcohols

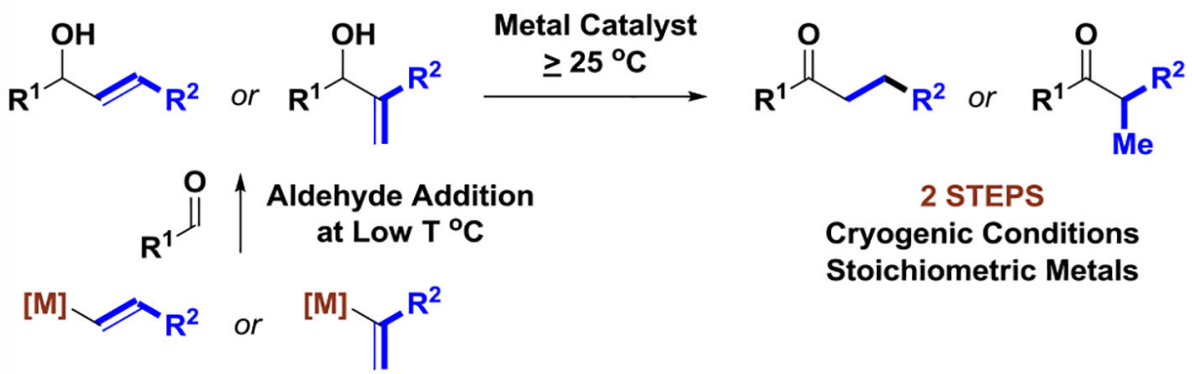

I $\underline{\text { his }}$ Work: Metal-Catalyzed Reductive Coupling-Internal Redox Isomerization

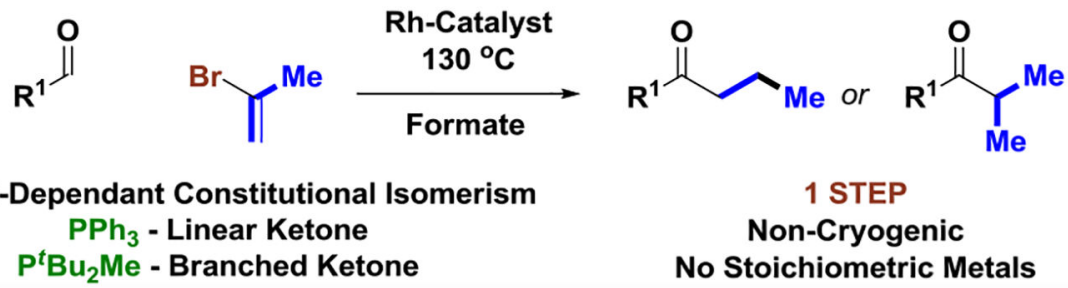

Figure 1.

Classical and contemporary strategies for the convergent construction of linear or branched alkyl ketones. 

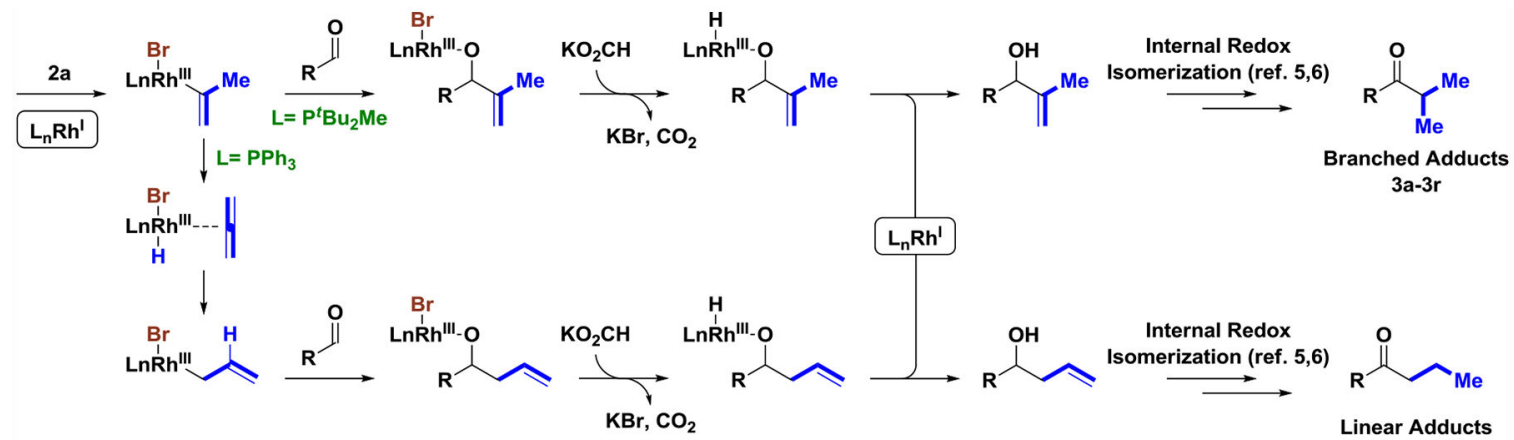

Scheme 1.

General catalytic mechanism accounting for regiodivergence in the rhodium-catalyzed aldehyde reductive coupling of 2-bromopropene $2 \mathbf{a}$ to form isomeric ketones $\mathbf{3 a}-\mathbf{3 r}$ and 4a-4r. Competing pathways involving $\beta$-hydride elimination from the kinetic rhodium alkoxide are not depicted. 
Table 1.

Selected optimization experiments in the rhodiumcatalyzed reductive coupling of 2-bromopropene 2a with piperonal $1 \mathbf{a}$ to form the isomeric ketones $3 \mathbf{a}$ or $\mathbf{4 a}{ }^{a}$<smiles>O=Cc1ccc2c(c1)OCO2</smiles>

$1 \mathrm{a}$ (100 mol\%)

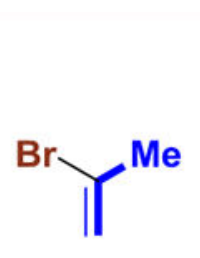

2a

\section{$\mathrm{Rh}$ (acac)(CO) 2 (5 mol\%)} ligand (11 $\mathrm{mol} \%)$ base $(100 \mathrm{~mol} \%)$ reductant (300 mol\%) DME (0.2 M) $130^{\circ} \mathrm{C}, 16 \mathrm{hr}$ (200 mol\%)

\begin{tabular}{|c|c|c|c|c|c|}
\hline entry & ligand & base & reductant & 3a (yield) & 4a (yield) \\
\hline 1 & $\mathrm{P}^{t} \mathrm{Bu}_{2} \mathrm{Me}$ & $\mathrm{CS}_{2} \mathrm{CO}_{3}$ & $\mathrm{NaO}_{2} \mathrm{CH}$ & $45 \%$ & --- \\
\hline 2 & $\mathrm{P}^{t} \mathrm{Bu}_{3}$ & $\mathrm{CS}_{2} \mathrm{CO}_{3}$ & $\mathrm{NaO}_{\mathrm{z}} \mathrm{CH}$ & $43 \%$ & $4 \%$ \\
\hline 3 & $\mathrm{PCy}_{3}$ & $\mathrm{CS}_{2} \mathrm{CO}_{3}$ & $\mathrm{NaO}_{\mathrm{z}} \mathrm{CH}$ & $28 \%$ & --- \\
\hline 4 & $\mathrm{P}^{t} \mathrm{Bu}_{2} \mathrm{Ph}$ & $\mathrm{CS}_{2} \mathrm{CO}_{3}$ & $\mathrm{NaO}_{2} \mathrm{CH}$ & $21 \%$ & $2 \%$ \\
\hline 5 & $\mathrm{P}^{t} \mathrm{BuPhj}$ & $\mathrm{GS}_{2} \mathrm{CO}_{3}$ & $\mathrm{NaO}_{2} \mathrm{CH}$ & $29 \%$ & $2 \%$ \\
\hline 6 & $\mathrm{PPh}_{3}$ & $\mathrm{GS}_{2} \mathrm{CO}_{3}$ & $\mathrm{NaO}_{2} \mathrm{CH}$ & --- & $48 \%$ \\
\hline 7 & dippf & $\mathrm{CS}_{2} \mathrm{CO}_{3}$ & $\mathrm{NaO}_{2} \mathrm{CH}$ & --- & $<5 \%$ \\
\hline 8 & dppe & $\mathrm{CS}_{2} \mathrm{CO}_{3}$ & $\mathrm{NaO}_{2} \mathrm{CH}$ & --- & $<5 \%$ \\
\hline 9 & dppp & $\mathrm{CS}_{2} \mathrm{CO}_{3}$ & $\mathrm{NaO}_{2} \mathrm{CH}$ & --- & $<5 \%$ \\
\hline 10 & dppb & $\mathrm{CS}_{2} \mathrm{CO}_{3}$ & $\mathrm{NaO}_{2} \mathrm{CH}$ & --- & $47 \%$ \\
\hline 11 & $\mathrm{PPh}_{3}$ & $\mathrm{~K}_{2} \mathrm{CO}_{3}$ & $\mathrm{NaO}_{2} \mathrm{CH}$ & --- & $50 \%$ \\
\hline 12 & $\mathrm{PPh}_{3}$ & $\mathrm{~K}_{2} \mathrm{CO}_{3}$ & $\mathrm{KO}_{2} \mathrm{CH}$ & --- & $77 \%$ \\
\hline $13^{b}$ & $\mathrm{PPh}_{3}$ & $\mathrm{~K}_{2} \mathrm{CO}_{3}$ & $\mathrm{ko}_{2} \mathrm{ch}$ & --- & $92 \%$ \\
\hline $14^{b}$ & $\mathrm{P}^{t} \mathrm{Bu}_{2} \mathrm{Me}$ & $\mathrm{k}_{2} \mathrm{CO}_{3}$ & $\mathrm{ko}_{2} \mathrm{ch}$ & $54 \%$ & --- \\
\hline $15^{b, c}$ & $\mathrm{P}^{t} \mathrm{Bu}_{2} \mathrm{Me}$ & $\mathrm{k}_{2} \mathrm{CO}_{3}$ & $\mathrm{ko}_{2} \mathrm{ch}$ & $80 \%$ & --- \\
\hline
\end{tabular}

${ }^{a}$ Yields are of chromatographically isolated isomerically pure (>20:1) material. $\mathrm{P}^{t} \mathrm{Bu}_{2} \mathrm{Me} \cdot \mathrm{HBF}_{4}, \mathrm{P}^{t_{\mathrm{Bu}}} \cdot \mathrm{HBF}_{4}$ and $\mathrm{P}{ }_{\mathrm{Bu}} \mathrm{Ph}(\mathrm{PhMe}, 50$ wt $\%)$ were used. Bidentate ligands (5.5 mol\%). See Supporting Information for experimental details.

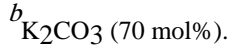

${ }^{c}$ DME (0.4 M). 


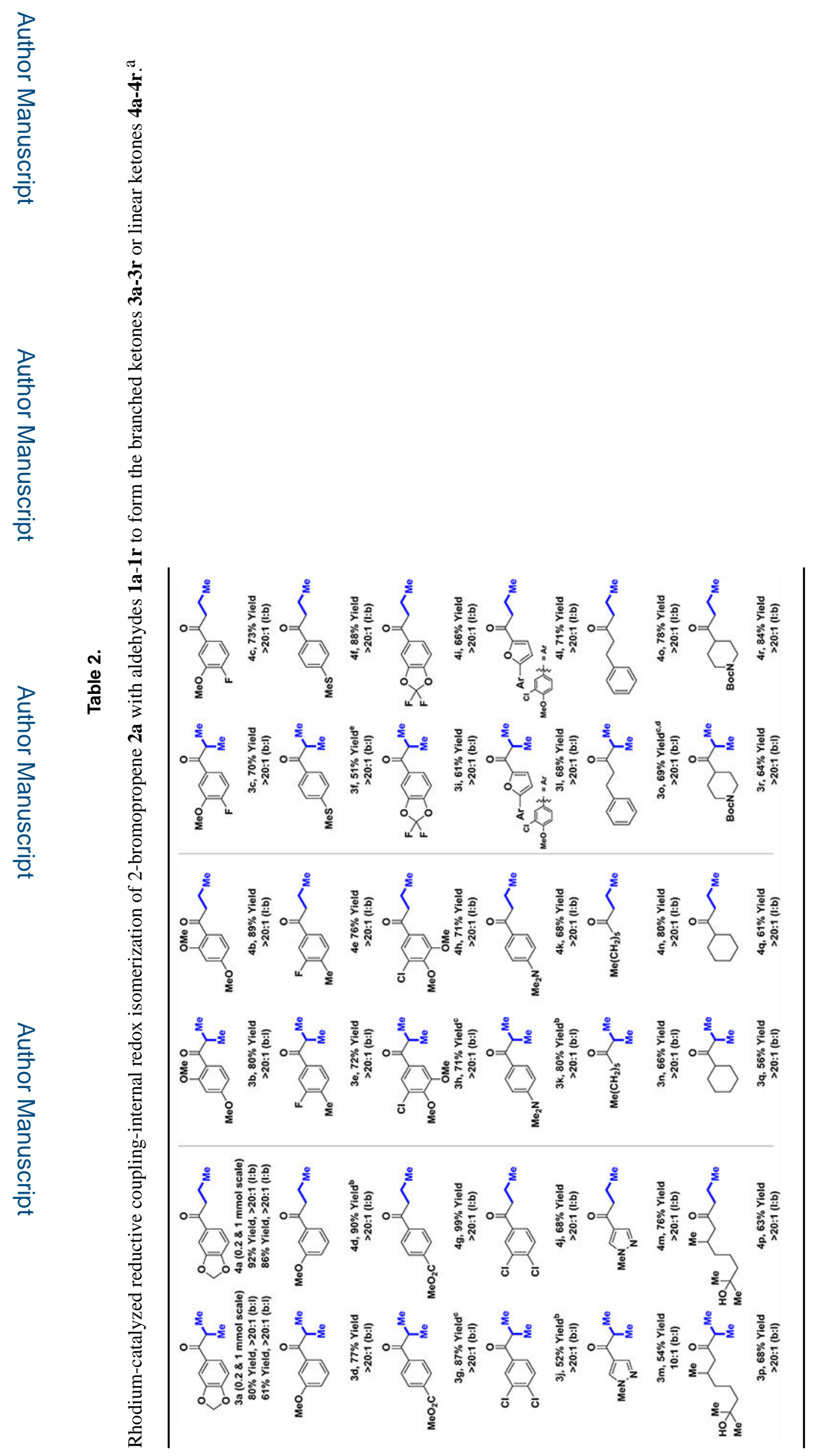

aStandard Conditions: [branched] Aldehyde 1a-1r (100 mol\%), 2-bromopropene (200 mol\%), Rh(acac)(CO)2 (5 mol\%), $\mathrm{P}^{t} \mathrm{Bu}_{2} \mathrm{Me} \bullet \mathrm{HBF}_{4}(11 \mathrm{~mol} \%), \mathrm{K}_{2} \mathrm{CO}_{3}(70 \mathrm{~mol} \%), \mathrm{KO}_{2} \mathrm{CH}(300 \mathrm{~mol} \%), \mathrm{DME}(0.4 \mathrm{M}), 130{ }^{\circ} \mathrm{C}$. [linear] Aldehyde 1a-1r $(100 \mathrm{~mol} \%)$ 2-bromopropene (200 mol\%), $\mathrm{Rh}(\mathrm{acac})(\mathrm{CO})_{2}(5 \mathrm{~mol} \%), \mathrm{PPh}_{3}(11 \mathrm{~mol} \%), \mathrm{K}_{2} \mathrm{CO}_{3}(70 \mathrm{~mol} \%), \mathrm{KO}_{2} \mathrm{CH}(300 \mathrm{~mol} \%) \mathrm{DME}(0.2 \mathrm{M})$, $130{ }^{\circ} \mathrm{C}$. 